\title{
Six-Sigma and Taguchi Approaches to the Printed Circuit Board Quality Improvement
}

\author{
Lai Wang Wang ${ }^{1} \&$ Quoc Liem Le ${ }^{1}$ \\ ${ }^{1}$ Department of Industrial Engineering and Management, National Kaohsiung University of Applied Sciences, \\ Kaohsiung, Taiwan \\ Correspondence: Quoc Liem Le, Department of Industrial Engineering and Management, National Kaohsiung \\ University of Applied Sciences, No. 415, JianGong Rd. Sanmin Dist., Kaohsiung 807, Taiwan.
}

Received: September 22, 2015

Accepted: October 12, 2015

Online Published: November 27, 2015

doi:10.5430/rwe.v6n4p29

URL: http://dx.doi.org/10.5430/rwe.v6n4p29

\begin{abstract}
Problem: The manufacturing of printed circuit board (PCB) has been popularly developed, which demands quality and being effective in increasing customers' satisfaction, decreasing costs, reducing defects and profitable warranty. However, practical experiences in the process of using statistic quality method - to be particularly significant in the manufacturing of PCB have shown over $60 \%$ of all circuit failures relating to the printing process which is the most critical step in PCB manufacturing.

Approach: The aims of this research are to apply the Six-Sigma DMAIC to reduce the defects and improve the quality of PCB. At the beginning steps, process capability analysis (PCA) is employed to inspect and analyze the current printing operations. Afterwards, Taguchi method is applied to design experiments, analyze the significant factors and determine the optimum settings.

Results: Taguchi is the core statistical tools for Six Sigma improvement and attaining a higher Six Sigma level, so by applying the optimal settings, the printing process can also be improved.

Keywords: quality, Six-Sigma improvement, DMAIC, Taguchi method

1. Introduction

Industries are continuously facing extreme competition and the challenge of meeting increasing demands for higher quality products at economic costs (Nguyen \& Tran, 2015). The success of an organization is directly related to how effective its implementation of continuous improvement is. Six-Sigma is an all-round and flexible system which can be used to obtain, maintain, and expand the success of a corporation. Its quality standard refers to a probability limitation of 3.4 errors out of a million operations during the manufacturing process (Harry \& Schroeder, 2000; Nguyen et al., 2015). For many manufacturing system, the Six-Sigma approach is an important continuous improvement methodology, which integrates with a business strategy based on execution of management by objectives, and effective project management with Define, Measure, Analyze, Improve, and Control (DMAIC) technique which is critical to attain excellent business performance.

A Six Sigma is a structured and disciplined process, focused on delivering perfect product or service to the customer on a consistent basis. Six sigma programs have performance metrics and measurements based on cost, quality, and schedules. This method implementation uses a systematic procedure including the five-step DMAIC (Define, Measure, Analyze, Improve, and Control) methodology. The performing at six Sigma level means producing only 3.4 defects out of every million opportunities for a business process. There has been a significant increase and development of six sigma technology and methodology in organizations. Especially in the last decade, as a change and improvement strategy, Six Sigma has received considerable attention in global companies in generating maximum business benefit and competitive advantage. DMAIC is a closed-loop process that eliminates unproductive steps, focuses on new measurements, and applies technology for continuous improvement.
\end{abstract}


Table 1. Six sigma levels and defects per million opportunities

\begin{tabular}{cccc}
\hline Sigma level & DPMO & Percent defective & Percentage yield \\
\hline 1 & 691,462 & $69 \%$ & $31 \%$ \\
2 & 308,538 & $31 \%$ & $69 \%$ \\
3 & 66,807 & $6.7 \%$ & $93.3 \%$ \\
4 & 6,210 & $0.62 \%$ & $99.38 \%$ \\
5 & 233 & $0.023 \%$ & $99.977 \%$ \\
6 & 3.4 & $0.00034 \%$ & $99.99966 \%$ \\
\hline
\end{tabular}

Table 2. Key steps of six sigma using DMAIC process

\begin{tabular}{|c|c|}
\hline Six Sigma steps & Key processes \\
\hline Define & $\begin{array}{l}\text {-Define the requirements and expectations of the customer } \\
\text {-Define the project boundaries } \\
\text {-Define the process by mapping the business flow }\end{array}$ \\
\hline Measure & $\begin{array}{l}\text {-Measure the process to satisfy customer's needs } \\
\text {-Develop a data collection plan } \\
\text {-Collect and compare data to determine issues and shortfalls }\end{array}$ \\
\hline Analyze & $\begin{array}{l}\text {-Analyze the causes of defects and sources of variation } \\
\text {-Determine the variations in the process }\end{array}$ \\
\hline Improve & $\begin{array}{l}\text {-Improve the process to eliminate variations } \\
\text {-Develop creative alternatives and implement enhanced plan }\end{array}$ \\
\hline Control & $\begin{array}{l}\text {-Control process variations to meet customer requirements } \\
\text {-Develop a strategy to monitor and control the improved } \\
\text { process } \\
\text { - Implement the improvements of systems and structures }\end{array}$ \\
\hline
\end{tabular}

A printed circuit board, or PCB, is a self-contained module of interconnected electronic components found in devices ranging from common beepers, or pagers, and radios to sophisticated radar and computer systems. The circuits are formed by a thin layer of conducting material deposited, or "printed," on the surface of a nonconductive board known as the substrate. Individual electronic components are placed on the surface of the substrate and soldered to the interconnecting circuits. Contact fingers along one or more edges of the substrate act as connectors to other PCBs or to external electrical devices such as on-off switches. A printed circuit board may have circuits that perform a single function, such as a signal amplifier, or multiple functions.

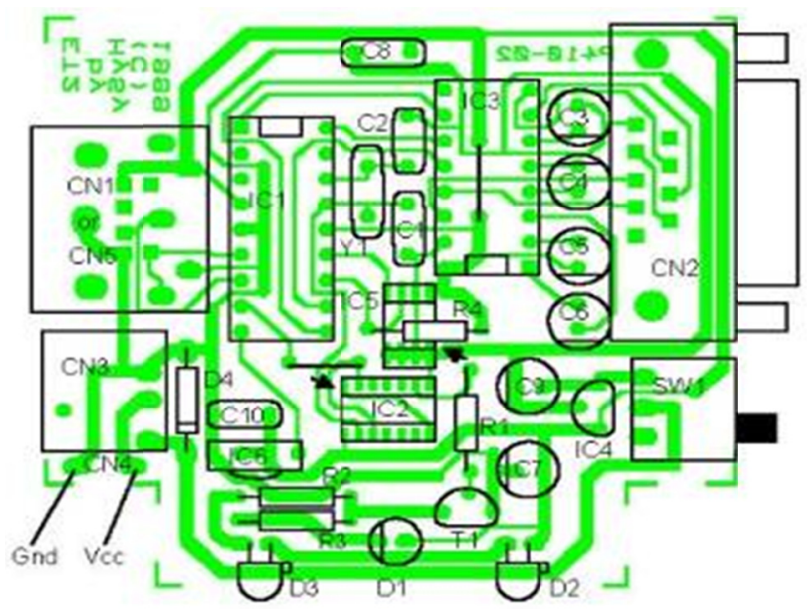

Figure 1. A layout of a typical circuit board on the design step 


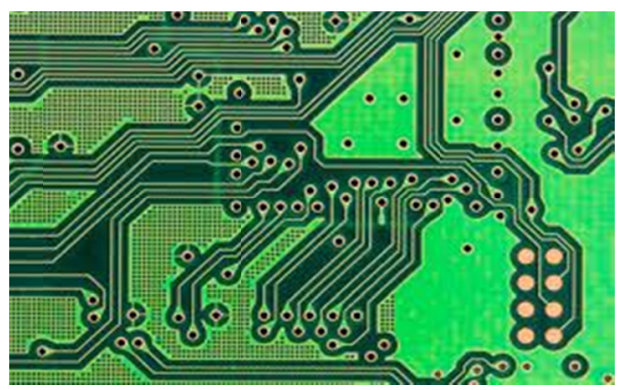

Figure 2. An example of circuit board

This case study was conducted to manufacture multi-layer PCBs using Surface mount technology (SMT), SMT is used extensively in the electronics industry. Surface-mounted components are often smaller than their leaded counterparts, and potentially more reliable products can be designed and manufactured using SMT. Solder paste stencil printing process is a very critical step in the surface-mount manufacturing process. Experience has shown that typically over $60 \%$ of all soldering defects are due to problems associated with the printing process. Therefore, the operation and the setup of the printing process are key elements that must be considered when trying to minimize defects. The main reason for printing solder paste onto the Printed Circuit Board (PCB) is to supply solder alloy for the solder joints. To achieve this objective, the solder paste print must be aligned correctly, the correct amount of solder paste for each joint must be assured and the print must be formed as an even layer of paste for perfect component placement.

Nowadays, the market demands increasingly complex electronic products in terms of specifications. The circuit of a PCB is becoming more and more delicate. Thus, quality excellence is so significant in the manufacture of PCBs. From the company's point of view, the printing process is the most crucial process that can affect the PCB quality. Without proper control of the printing process, common printing problems such as bridging, open circuit, spur and mouse bite can occur.

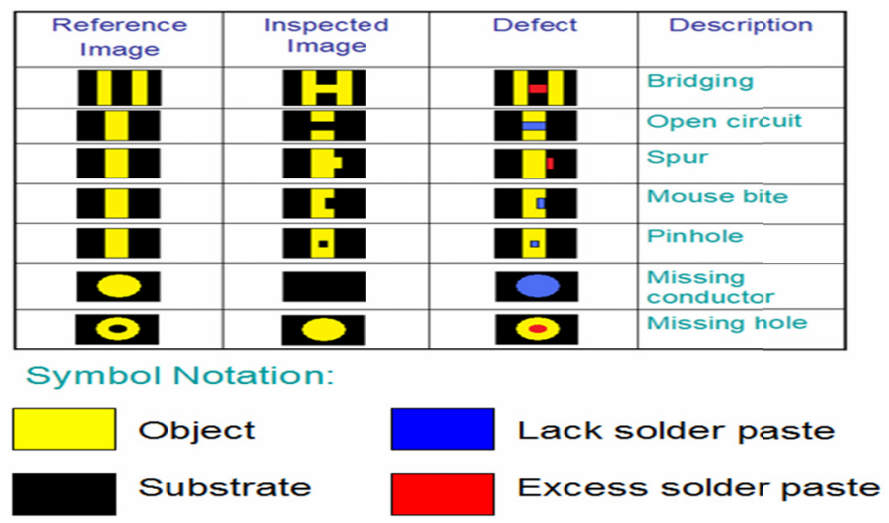

Figure 3. Seven types of defects on the PCB layer

According to the current process capability study, the sigma level of the printing process was not very satisfactory. Therefore, this study was conducted in the printing process with the objectives of improving the sigma level for products of a PCB company.

This study aims at improving the quality of PCB using six sigma DMAIC methodologies. The case study was required to improve the quality of the product for its customer satisfaction. The objectives of the study are: (1) to research and identify quality problems; (2) to present commonly used six sigma tools and techniques; (3) to solve the quality related problems and increase quality of the product by using Six Sigma DMAIC methodology.

This research applies the Six-Sigma DMAIC (Define, Measure, Analyze, Improve and Control) approach to reducing the defects and improving the quality of PCB. At the beginning steps, process capability analysis (PCA) is used to inspect and analyze the present printing operation. Afterwards, Taguchi method is used to design experiment, analyze the significant factors and determine the optimal settings. By applying the optimal settings, the printing process can be improved and a higher Six Sigma level can be attained. 


\section{Literature Review}

\subsection{Introduction to Printing Process}

The printing process is a manufacturing process that transfers solder paste onto the solder pad of a PCB. The application method of solder paste is printing and the printing technique used is off-contact printing in which there is a snap-off distance between a stencil and a PCB. The type of printing machine used to manufacture products is semi-automatic. During a printing process, two PCBs are placed side-by-side on the solder of a printing machine. The solder paste is then manually placed onto a stencil before printing. The front/back blade of squeegee makes line contact with the stencil and close contact with the given amount of solder paste. The solder paste is then rolled in front of the front/back blade. In this way, solder paste is pressed against the stencil and transferred onto the solder pad through the stencil opening. The operation of a printing machine is shown in Figure 3.

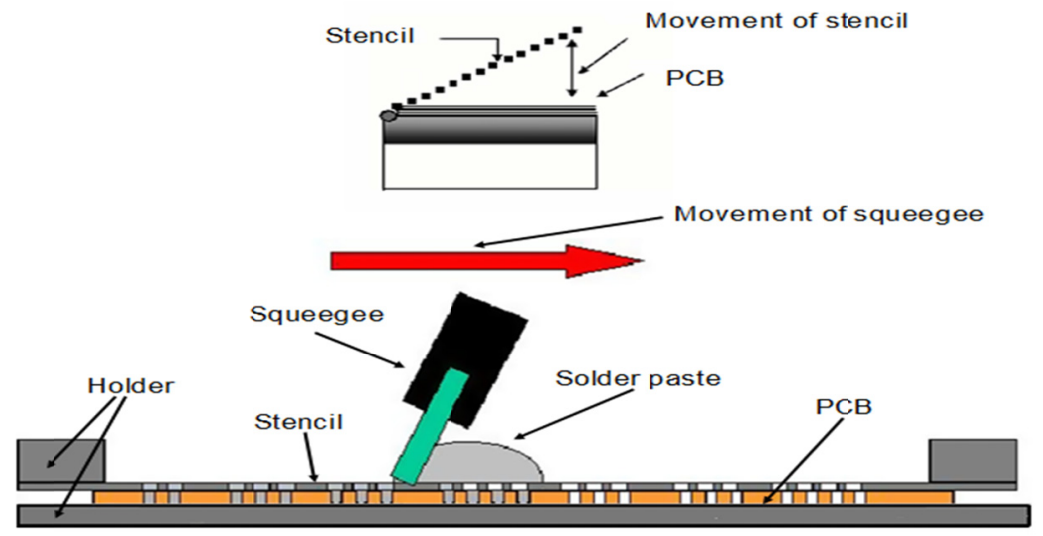

Figure 4 . The operation of the printing process

\subsubsection{Stencil}

Stencils can be made of different materials. Besides stainless steel, they can be made of copper, bronze, nickel or plastic. There are three different stencil-manufacturing methods: Etching, electroforming and laser cutting. The apertures in both laser-cut and electroformed stencils have very sharp edges and are slightly conic. This makes the solder paste slip easily off the aperture edges and thereby secures a uniform print. The metal stencils are attached to the printing frame using tensioned mesh or directly using a special frame with gripping systems, which can easily damage the stencils and thereby resulting in poor printing quality. The thickness of the metal stencil is typically 150 microns but 100,125 and 200 microns are also available. The thickness should be chosen based on the job in hand. For very fine pitch such as $0.3 \mathrm{~mm}$ lead pitch, 100 or 125 -micron stencils could be used and for lead pitch down to $0.5 \mathrm{~mm}$, 150-micron stencils can be used. The stencil thickness together with the aperture size also determines the amount of solder paste present to form each solder joint during reflow soldering. As a guideline, the minimum stencil aperture width must be at least 3 times (preferable 5 times) the diameter of the largest solder particle and the stencil aperture width should also be larger than the stencil thickness. Rounded aperture corners will reduce clogging of fine pitch apertures and smearing. The top surface of the metal stencil should be slightly roughened to achieve a perfect solder paste roll during printing.

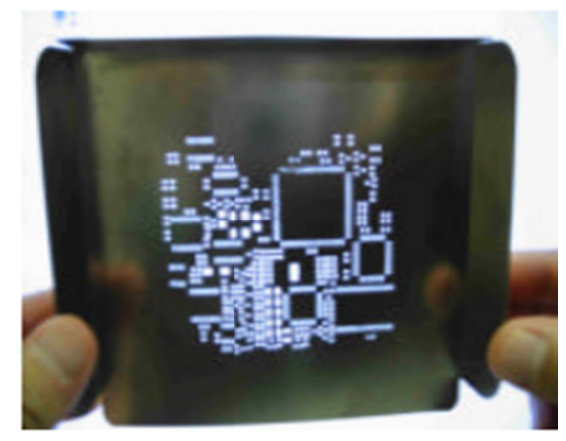

Figure 5. An example of metal stencil [24] 


\subsubsection{Squeegee and Solder Paste}

In this study, the squeegee system consists of the front and back blades, there are two types of printing, front printing and back printing. In current practice, both front and back printing are used alternately during printing.

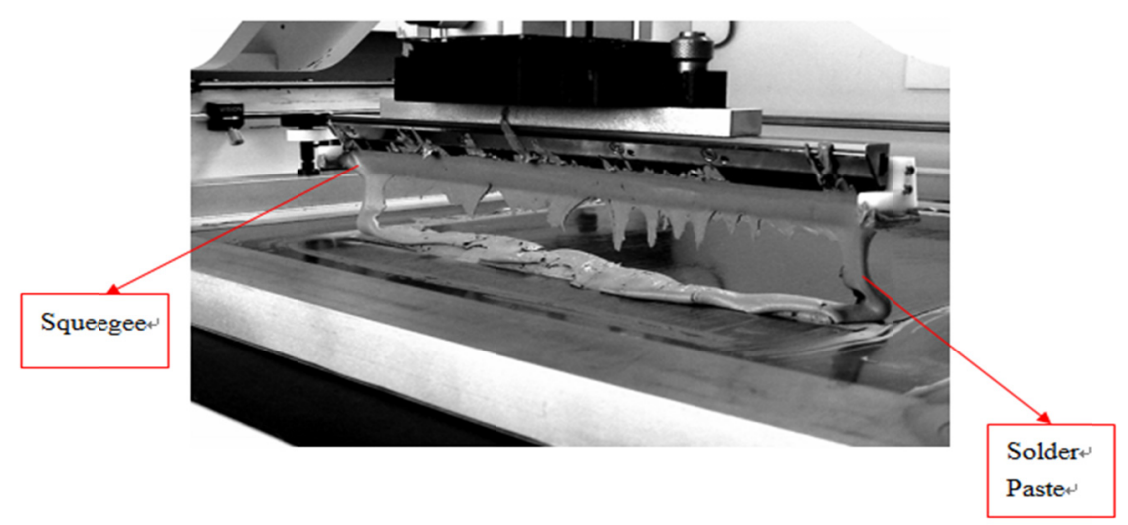

Figure 6. A printing machine
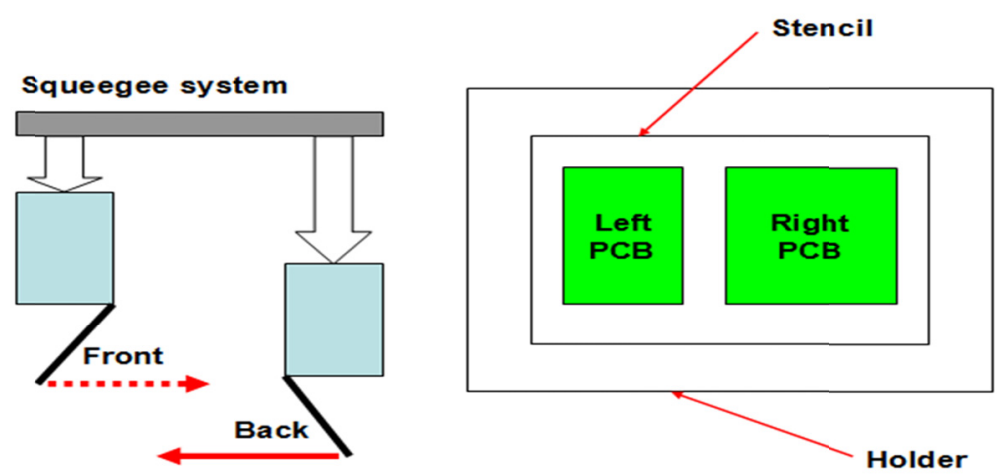

Figure 7. The operation of squeegee system

Solder paste characteristics must be carefully controlled to achieve optimum production results. These include: percent of metal, viscosity, slump, solder balls, flux activity working life and shelf life.

\subsection{Six Sigma}

Over the years, many researchers have studied Six Sigma programs and identified many critical decisions of these programs. For example, see the previous research of Antony \& Banuelas (2002); Coronado \& Antony (2002); Lynch et al. (2003); Mcadam \& Evans (2004); Szeto \& Tsang (2005); and Savolainen \& Haikonen (2007).

Six Sigma is the widely recognized as a business strategy that employs statistical and non- statistical tools and techniques, change management tools, project management skills, teamwork skills and a powerful roadmap (DMAIC) to maximize an organization's return on investment (ROI) through the elimination of defects in processes.

Hoerl (2001) and Montgomery (2008) discuss the six sigma method from the statistical, probabilistic and the quantitative point of view. From the statistical point of view, the term six sigma is defined as having less than 3.4 defects per million opportunities or a success rate of $99.9997 \%$ where sigma is a term used to represent the variation about the process average Antony \& Banuelas (2002). Motorola was the first organization to use the term six sigma in the 1980s as the part of its quality performance measurement and improvement program. The concept behind this method was developed by William Smith to deal with high failure rate experienced by the system produced. Smith proposed Six Sigma as tool to improve reliability and the quality of products. The application of the six sigma methods allowed many organizations to sustain their competition advantage by integrating their knowledge of the process with statistic, engineering, and the project management. A Six Sigma has since been successfully applied in manufacturing organizations such as General Electric, Boeing, DuPont, Toshiba, Seagate, Applied Signal, Kodak, Honeywell, Texas 
Instruments, Sony, etc. Numerous books and articles also address the basic concepts and benefits of the six sigma method (Harry \& Schroeder, 2000 and Hoerl, 2001).

A Six sigma methodology improves any existing business process by constantly reviewing and re-turning the process. To achieve an objective, Six Sigma uses a five steps methodology known as DMAIC. It is one of most common methodologies for tackling existing products or processes which did not meet customer specification or did not perform effectively and for looking for incremental improvement (Lee-Mortimer, 2006)

\subsection{Introduction to Taguchi Method}

Taguchi method is a technique for designing and performing experiments to investigate processes where the output depends on many factors (variables, inputs) without having tediously and uneconomically run of the process using all possible combinations of values.

In Taguchi methodology, the desired design is finalized by selecting the best performance under given constrained conditions. The tool used in the Taguchi method is the orthogonal array (OA). OA is the matrix of numbers arranged in columns and rows. The Taguchi method employs a generic signal-to-noise $(\mathrm{S} / \mathrm{N})$ ratio to quantify existing variation. These $\mathrm{S} / \mathrm{N}$ ratios are used as measures of the effect of noise factors on performance characteristics. $\mathrm{S} / \mathrm{N}$ ratios take into account both amount of variability in the response data and closeness of the average response to target. There are several $\mathrm{S} / \mathrm{N}$ ratios available depending on type of characteristics, i.e., smaller is better, nominal is best (NB) and larger is better.

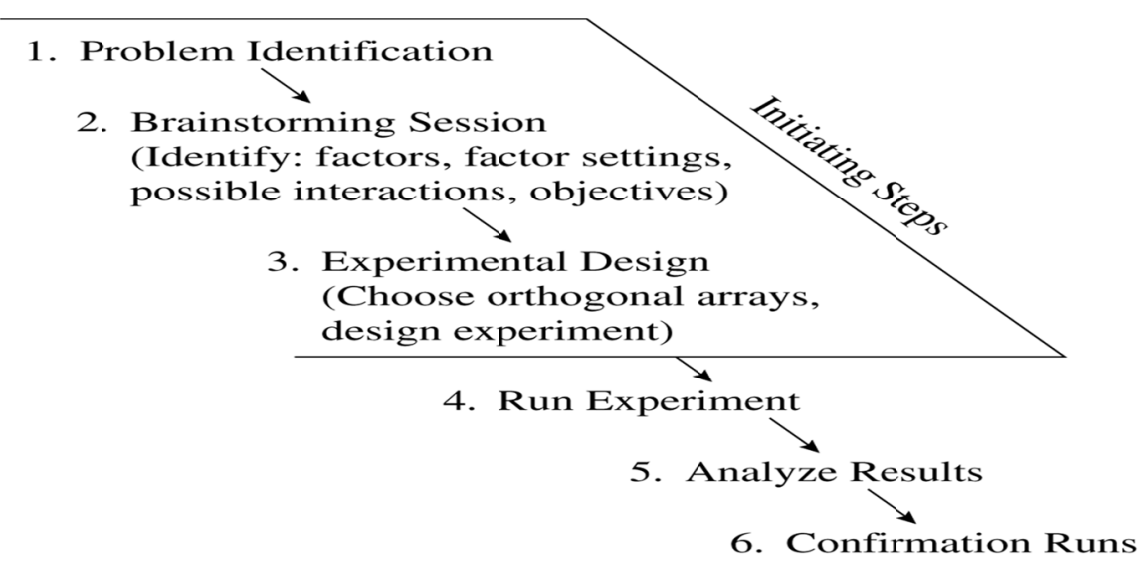

Figure 8. The Taguchi process

\section{Methodology}

\subsection{Six-Sigma DMAIC}

DMAIC is a structured problem-solving procedure widely used in quality and process improvement. It is often associated with Six Sigma activities, and almost all implementations of Six Sigma use the DMAIC problem solving process for project management and completion. The letters DMAIC form an acronym for the five steps, Define, Measure, Analyze, Improve, and Control. Notice that there are "tollgates" between each of the major steps in DMAIC. Tollgates are where the project is reviewed to ensure that it is on track and they provide a continuing opportunity to evaluate whether the team can successfully complete the project on schedule. Tollgates also present an opportunity to provide guidance regarding the use of specific technical tools and other information about the problem. Organization problems and other barriers to success-and strategies for dealing with them-also often are identified during tollgate reviews. Tollgates are critical to the all problem-solving process. It is important that these reviews be conducted very soon after the team completes each step (Montgomery, 2008).

\subsubsection{Define}

When implementing the Six-Sigma DMAIC approach, the most important thing is to define the scope of a problem. During the selection of a project, customers' requirements and goals have to be clearly determined at first. At this stage it should be decided whether the process or the product needs to be improved. Afterwards, the critical to quality characteristics (CTQ) need to be selected as to what critical quality characteristics need to be met in order for the product to satisfy customers' needs. After customers' requirements have been determined, the next step would be to 
evaluate their priority. Problems of higher urgency and importance shall be improved first. Lastly, the performance standard has to be defined to prioritize the improvements and evaluate various influences of the errors. The goal of the performance system is to convert customers' needs into process requirements, and the outputs of the process have to fall within specification limits accepted by customers.

\subsubsection{Measure}

The most important thing in the measurement stage is to verify the measurement system, because only when the system is accurate and reliable the root causes of a problem can then be clearly identified. Implementing a measurement system analysis includes two major items: correctness of the data and accuracy of the measurement system. A measurement system has to be assessed for its resolution, preciseness, bias, repeatability, and reproducibility. The assessment is carried out in the following steps:

\subsubsection{Collection of Data}

Randomly select the parts and the operators. Measurement of the selected parts is conducted repeatedly by the operators in a random order.

\subsubsection{Analysis of Variance}

Analyze if the part being measured, where measurement operators and the interaction have any significant influence on measurement results. If the $\mathrm{P}$ value of the interaction is greater than 0.05 , the interaction is not significant and can be ignored.

\subsubsection{Gauge Repeatability and Reproducibility (R\&R) Analysis}

Measure the variance of the systems, the gauge $R \& R$ including data analysis.

Data analysis: The measurement system evaluation standard is shown in Table 3. If \%Study Var is smaller than 10\%, it is considered as a good measurement system. It would be an acceptable measurement system if the value ranges between $10 \%$ and $30 \%$. It is not considered as a good measurement system if the value is greater than $30 \%$.

Table 3. Measurement system evaluation standard

\begin{tabular}{ll}
\hline Acceptable & \%Study Var $\leqq 10 \%$ \\
\hline Attention & $10 \%<\%$ Study Var $\leqq 30 \%$ \\
\hline Reject & $30 \%<\%$ Study Var \\
\hline
\end{tabular}

\subsubsection{Analyze}

At this stage, it is necessary to determine the sources of variation, find the reasons why there are errors, and then categorize the reasons that exist in different types. This means to find out what inputs influence the outputs and to identify the critical input factors that influence the results. To achieve this, the Cause and Effect Diagram is used in the current study.

\subsubsection{Improve}

In this phase, DOE was used as a core statistical tool for the sigma level improvement. The DOE steps are defined as finding out the response or output, identifying factors for the study, determining factor levels and range of factor setting. Taguchi method was used to select appropriate experimental design, run the experiment, collect and analyze the data, find out the results and draw conclusion.

\subsubsection{Control}

This stage is to implement a process control system, establish standard documentation, and continue to record and observe the process, so the key factors can be identified that over time the determined optimal setting does not get lost.

\subsection{Design Process of Taguchi Method}

The Taguchi method involves reducing the variation in a process through robust design of experiments. The overall objective of the method is to produce high quality product at low cost for the manufacturer. Taguchi developed a method for designing experiments to investigate how different parameters affect the mean and variance of a process performance characteristic that defines how well the process is functioning. The experimental design proposed by Taguchi involves using orthogonal arrays to organize the parameters affecting the process and the levels at which they should be changed. Instead of having to test all possible combinations like the factorial design, the Taguchi method 
tests pairs of combinations. This allows most the collection of the necessary data to determine which factors affect product quality with a minimum amount of experimentation, thus saving time and resources. Taguchi method is best used when there are an intermediate number of variables, few interactions between variables, and when only a few variables contribute significantly. The following are some basic steps of Taguchi method.

Step 1: Identify quality characteristics

The beginning of experiment, this method needs to define the process objectives or target values for a performance measure of the process; for example, forming load, temperature or quality, and so on. The goal of a process may also be a minimum or maximum; for example, the goal may be to minimize forming load. The deviation in the performance characteristic from the target value is used to define the loss function for the process.

Step 2: Determine the design parameters affecting the process

Parameters are variables within the process that affect the performance measure such as temperatures, pressures, and so on, that can be easily controlled. The number of levels that the parameters should be varied must be specified. For example, a temperature might be varied in between low and high values.

Step 3: Determine orthogonal arrays

Orthogonal array is chosen based on the number of parameters and the levels of variation for each parameter. For example, for four control factors and each factor has two levels, so there are sixteen combinations in Taguchi experiment and the full orthogonal array L16(24) is used for this case.

Step 4: Conducting the experiments and record results

After the factors are set up completely then the experiments will be conducted. After the experiments run finished, we can measure the parameters and experiment data.

Step 5: Data analysis

Complete data analysis to determine the effect of the different parameters on the performance measure.

Signal-to-noise: To determine the effect each variable has on the output, the signal-to-noise ratio, or the S/N number, needs to be calculated for each experiment conducted. Depending on output quality characteristic, $\mathrm{S} / \mathrm{N}$ ratio has three common kinds of $\mathrm{S} / \mathrm{N}$ as below:

* Smaller the better:

$$
\frac{S}{N}=-10 \log \left(\frac{1}{n} \sum_{i=1}^{n} y_{i}^{2}\right)
$$

Where, S/N: Signal to noise ratio, n: Number of experiments

yi: Experimental values

* Larger the better:

$$
\frac{S}{N}=-10 \log \left(\frac{1}{n} \sum_{i=1}^{n}\left(\frac{1}{y_{i}}\right)^{2}\right)
$$

Where, S/N: Signal to noise ratio, n: Number of experiments

yi: Experimental values

* Nominal the best

$$
\frac{S}{N}=-10 \log \left(\frac{1}{n} \sum_{i=1}^{n}\left(y_{i}-m\right)^{2}\right)
$$

Where, S/N: Signal to noise ratio, n: Number of experiments

yi: Experimental values, m: Target value of result

From signal to noise analyzing, the results can be estimated to find out the best product quality or process through making tabular below: 
Table 4. An Example for Taguchi Orthogonal Array $\mathrm{L}_{8}$

\begin{tabular}{cccccc}
\hline Experiment & Factor 1 & Factor 2 & Factor 3 & Factor $\mathbf{4}$ & S/N \\
\hline 1 & 1 & 1 & 1 & 1 & SN1 \\
2 & 1 & 1 & 1 & 2 & SN2 \\
3 & 1 & 2 & 2 & 1 & SN3 \\
4 & 1 & 2 & 2 & 2 & SN4 \\
5 & 2 & 1 & 2 & 1 & SN5 \\
6 & 2 & 1 & 2 & 2 & SN6 \\
7 & 2 & 2 & 1 & 1 & SN7 \\
8 & 2 & 2 & 1 & 2 & SN8 \\
\hline
\end{tabular}

In order to understand more clearly about this method, this research applied Taguchi experiment and the experiment would be conducted in the later chapter.

Step 6: Confirmation experiment

Running the experiments at the optimum condition is the final necessary step. So the process will be able to find out the best process or product quality.

A Taguchi experiment processes are summarized as flow chart below:

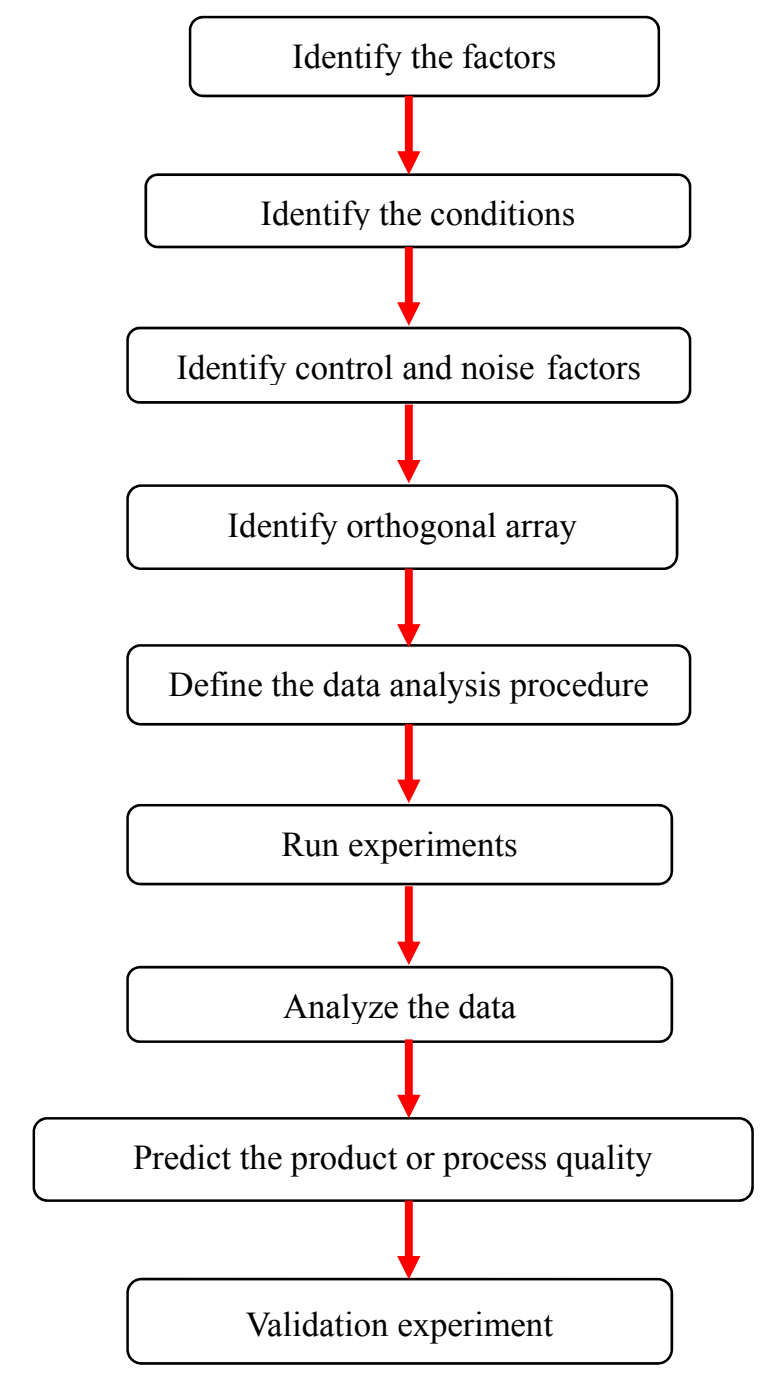

Figure 9. Taguchi experiment flow chart 
Orthogonal arrays have a balancing property in which every factor setting occurs for the same number of times for every setting of all other factors in the experiment. Orthogonal arrays allow researchers or designers to study many design parameters simultaneously and can be used to estimate the effects of each factor independent of other factors. Therefore, the information about the design parameters can be obtained with minimum time and resources. The signal-to-noise ratio is simply a quality indicator by which the experimenters and designers can evaluate the effect of changing a particular design parameter on the performance of the process or product.

In analyzing the simulation results, the nominal is the best characteristic of the Taguchi method is used to calculate the signal-to-noise $(\mathrm{S} / \mathrm{N})$ ratio that can identify the significant process parameters and optimize the PCB process.

\section{DMAIC Approach to Improve Quality of PCB}

This research is to apply the Six-Sigma with DMAIC (Define, Measure, Analyze, Improve, and Control) approach to reduce the defects of printed circuit boards (PCB), where the focus is on the printing process. The process, description, and techniques used are described in Table 5.

Table 5. Description and technique in each step of DMAIC in the study case

\begin{tabular}{lll}
\hline Process & \multicolumn{1}{c}{ Description } & Technique \\
\hline \multirow{3}{*}{ Define (D) } & 1. Define a problem & \\
& 2.Identify the CTQ characteristics & \\
& 3.Establish project improvement goals & Pareto chart \\
Measure (M) & $\begin{array}{l}\text { 1. Vegin the process } \\
\text { 2. Determify the measurement system }\end{array}$ & Gage R\&R \\
Analyze (A) & $\begin{array}{l}\text { 1. Data collection plan capability } \\
\text { 2. Identify the sources of variation }\end{array}$ & Histogram \\
& 1. Find some critical factors & Brainstorming \\
Improve (I) & $\begin{array}{l}\text { 2. Carry out the design of experiment for the } \\
\text { critical factors }\end{array}$ & Taguchi method \\
& 1. Implement the process control system & \\
Control (C) & 2. Establish standard documentation & Control plan \\
\end{tabular}

\subsection{Define Phase}

The lots of product rejected by the customer in two months were checked. The results of inspection on the types of defects on the PCB after screening process that contributed to the customer rejection or complaints are shown in Table 6.

Table 6. Defects of PCB on two months

\begin{tabular}{lll}
\hline Description Defects & October & November \\
\hline Bridging & 797 & 845 \\
Open circuit & 341 & 418 \\
Spur & 65 & 78 \\
Mouse bite & 32 & 41 \\
Pinhole & 20 & 30 \\
Missing conductor & 8 & 14 \\
Missing hole & 5 & 9 \\
\hline Total & 1268 & 1435 \\
\hline
\end{tabular}




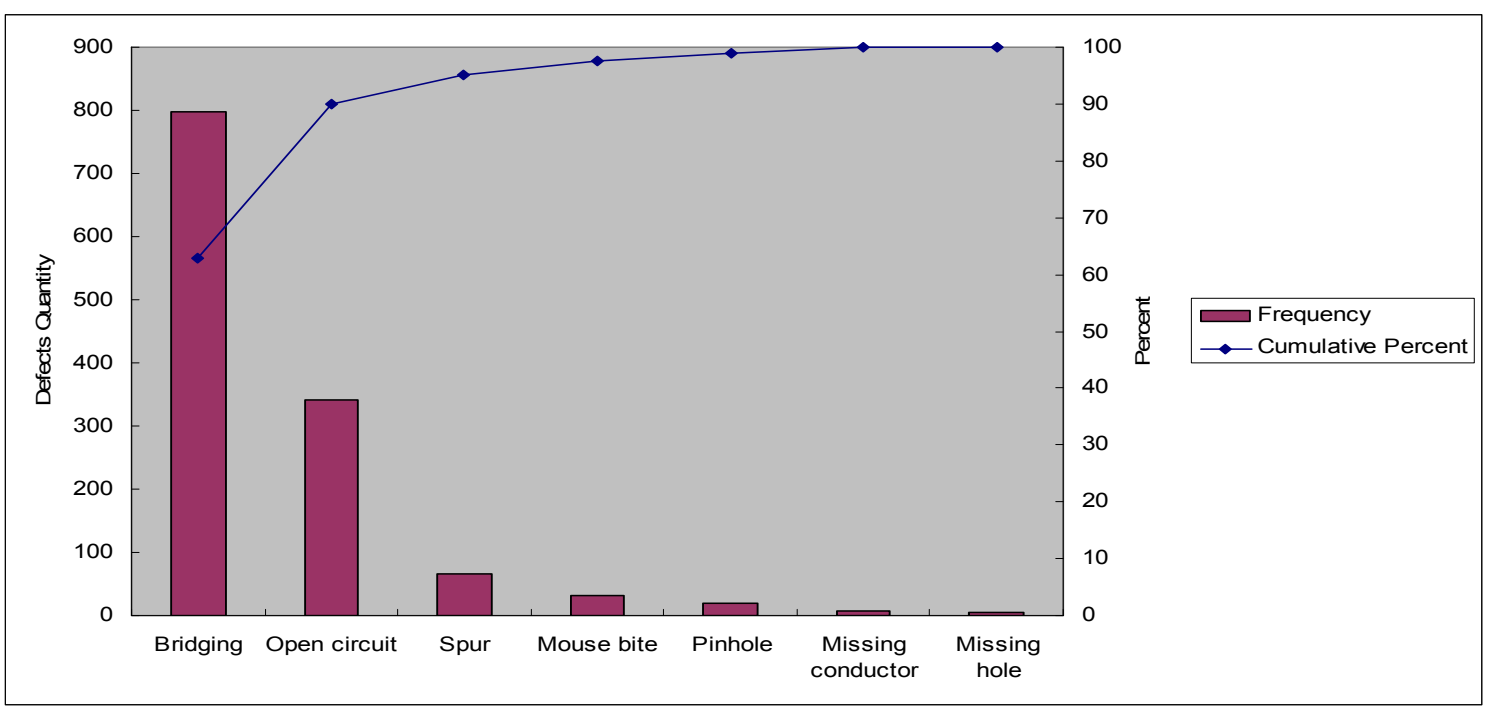

Figure 10. Pareto charts for screening process defects in October

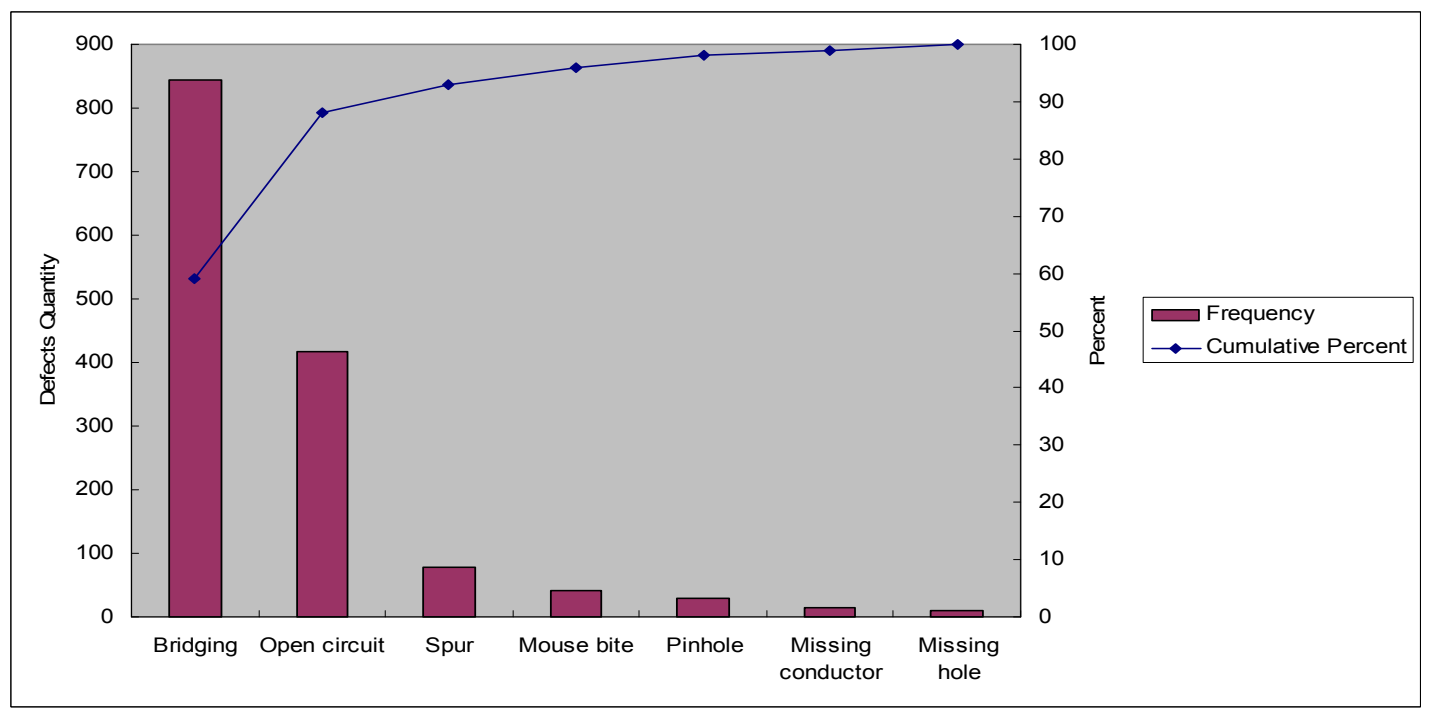

Figure 11. Pareto charts for screening process defects in November

Pareto charts revealed that Bridging and Open circuit have the largest quantity of defects. Because too less solder paste can cause open circuits and too more solder paste can cause bridging between solder pads in the subsequent processes. Thus, the solder paste height on the solder pads is identified as a critical to quality (CTQ) characteristic that needs to be controlled in a very precise way by the case of study.

\subsection{Measure Phase}

\subsubsection{Introducing the Measurement System}

Regarding the improvement of the printing process, the Solder Paste Height Measurement System SPM-300-3D is used and this equipment is verified for its measurement system.

\section{a. The description of this equipment}




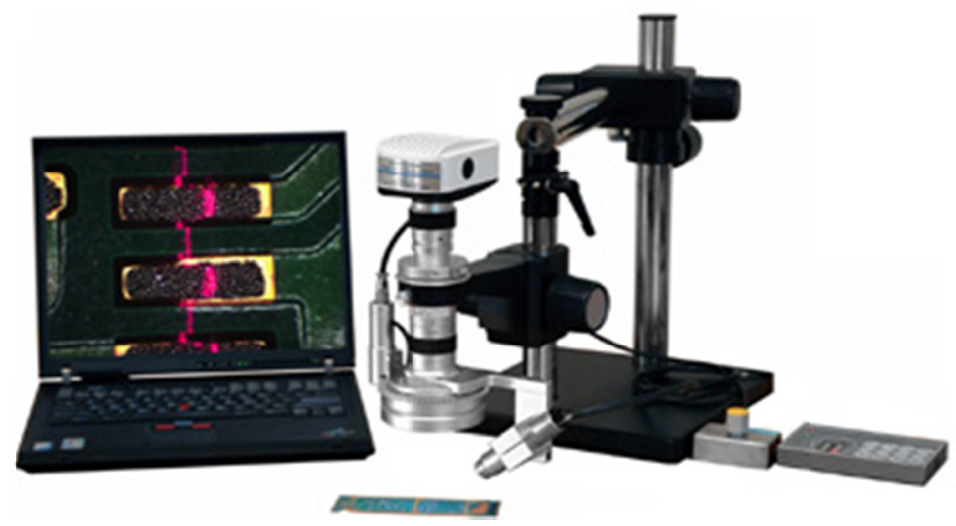

Figure 12. Solder paste height measurement system SPM-300-3D

The system is completed with mega pixel digital camera, zoom optic 50x-300x, laser light, rotational view and measurement software for your Windows/Pentium computer.

\section{b. The principle of this equipment}

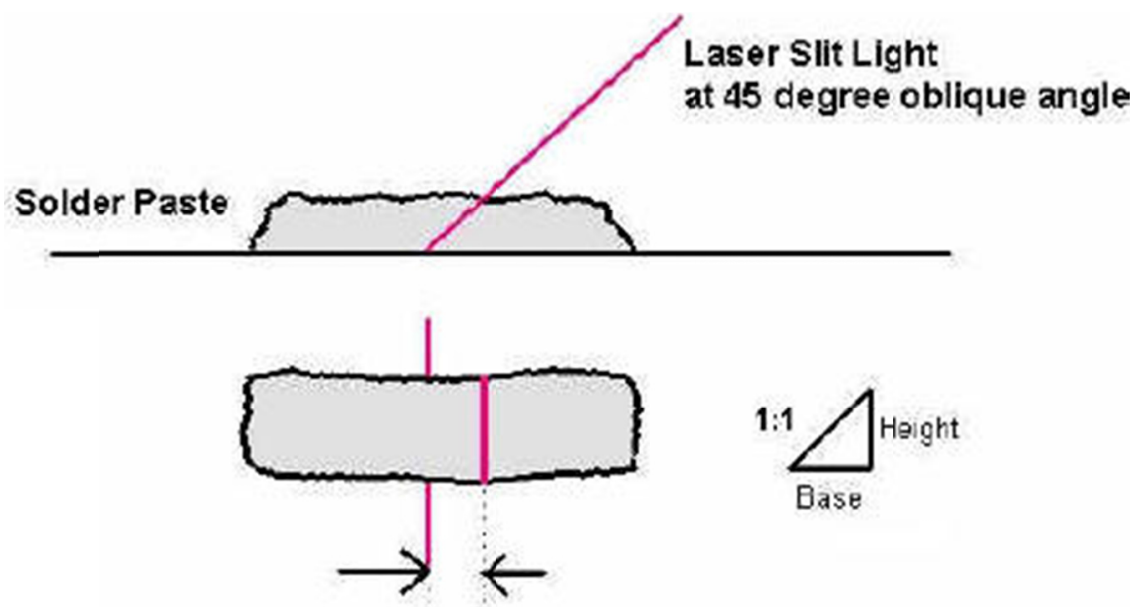

Figure 13. The principle of solder paste height measurement system SPM-300-3D

The SPM-300 projects a thin slice of laser light through a focusing lens onto the solder paste. This extremely thin slice of laser light intersects the top portion of solder paste first before reaching the board, which produces an offset of two lines due to height difference. Since this laser light is aligned at 45 degree, the profile of lines is in one to one (1:1) correspondent with the Z-Axis (Height Profile) of solder paste being measured. Then just measure the distance between these two lines to obtain Z-Height data. One can also measure any X-Y distances and area on the solder paste to calculate for volume.

\section{c. Verifying the measurement system}

For the study, ten random PCBs were selected from the manufacturing process. Two operators were chosen to participate in the study. Each part was measured three times by each operator. Analyze the measurement ability (repeatability and reproducibility). Minitab is applied for Gauge R\&R analysis. The results are shown in Figure 14 and Figure 15. 


\begin{tabular}{|c|c|c|c|c|}
\hline Gage R\&R & & & & \\
\hline Source & VarComp & $\begin{array}{l}\text { ontribution } \\
\text { fVarcomp) }\end{array}$ & & \\
\hline Total Gage R\&R & 0.002340 & 0.46 & & \\
\hline Repeatability & 0.002018 & 0.40 & & \\
\hline Reproducibility & 0.000322 & 0.06 & & \\
\hline Operator & 0.000000 & 0.00 & & \\
\hline Operator $\star$ Part & 0.000322 & 0.06 & & \\
\hline Part-To-Part & 0.505720 & 99.54 & & \\
\hline Total Variation & 0.508060 & 100.00 & & \\
\hline Source & StdDev (SD) & $\begin{array}{r}\text { Study } \operatorname{Var} \\
(6 \star S D)\end{array}$ & $\begin{array}{r}\text { sStudy Var } \\
\text { (\$SV) }\end{array}$ & $\begin{array}{l}\text { solerance } \\
\text { (SV/Toler) }\end{array}$ \\
\hline Total Gage RaR & 0.048373 & 0.29024 & $<6.79$ & 3.63 \\
\hline Repeatability & 0.044926 & 0.26956 & 6.30 & 3.37 \\
\hline Reproducibility & 0.017933 & 0.10760 & 2.52 & 1.35 \\
\hline Operator & 0.000000 & 0.00000 & 0.00 & 0.00 \\
\hline Operator*Part & 0.017933 & 0.10760 & 2.52 & 1.35 \\
\hline Part-To-Part & 0.711140 & 4.26684 & 99.77 & 53.34 \\
\hline Total Variation & 0.712783 & 4.27670 & 100.00 & 53.46 \\
\hline
\end{tabular}

Figure 14. SPM-300-3D Gauge R\&R analysis table

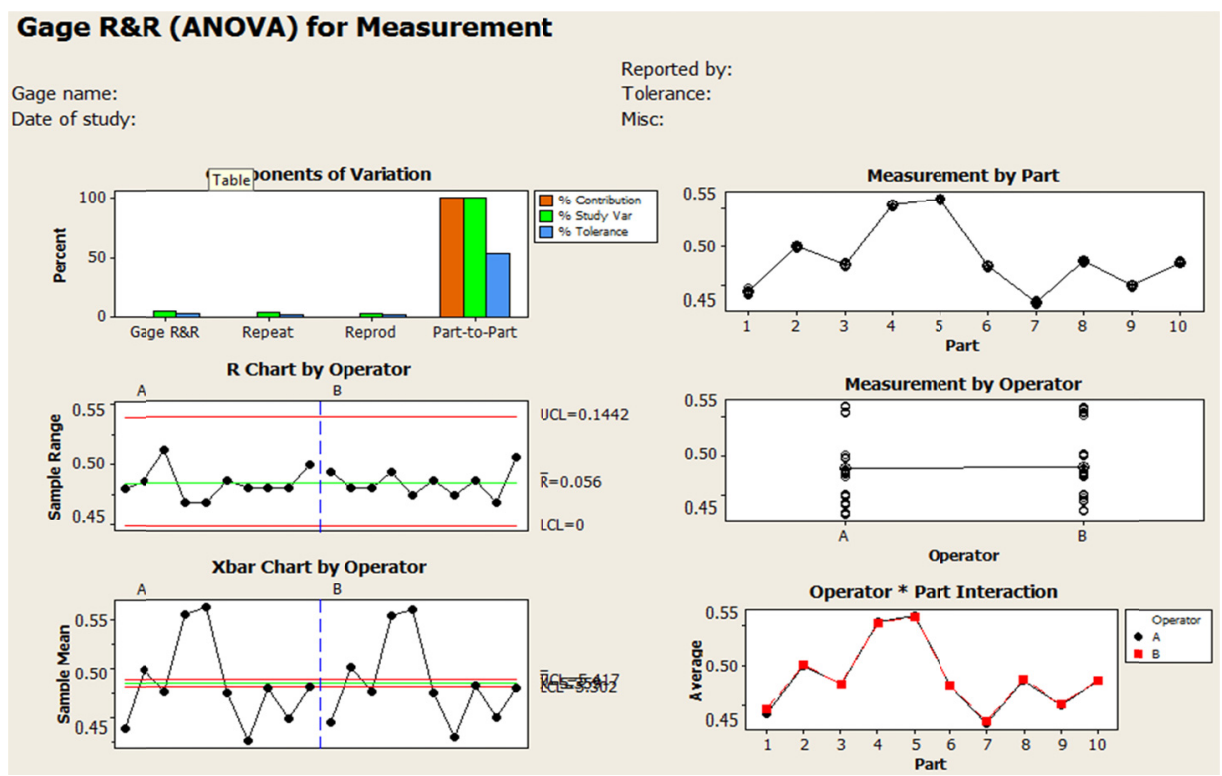

Figure 15. SPM-300-3D Gauge R\&R analysis diagrams

Based on the data analysis in Figures 14 and 15, it can be concluded that:

+ Contribution $\%($ Total Gage R\&R $)=0.46 \%<9 \%$

+ Contribution\% (Part to Part) $=99.54 \%$

$+\mathrm{P} / \mathrm{SV} \%(\%$ Study Var $)=6.79 \%<30 \%$ 


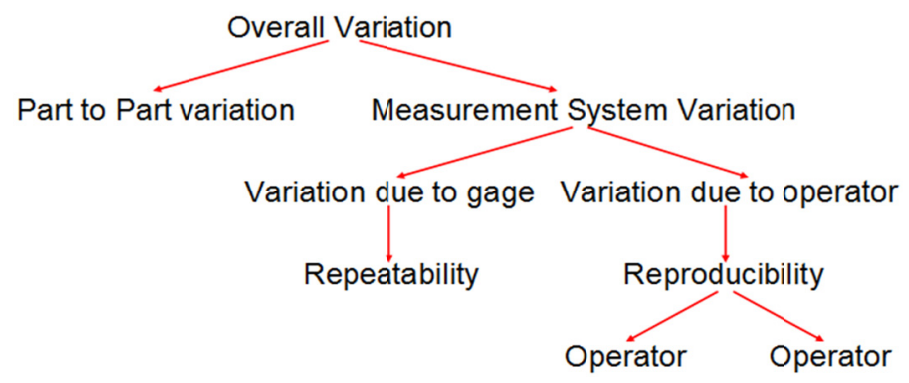

Figure 16. Overall variation

Figure 14 shows the analysis of variance for SPM-300-3D equipment. Based on the P-values (\%Contribution column in the Gage R\&R Analysis Table), we conclude that the effect of parts is large (99.54\%), operators and part-operator interaction may have a small effect. According to Figure 14 displays Total gage $R \& R=0.46 \%$ and Figure 15 we can conclude that the measurement system is acceptable.

\subsubsection{Determine the Process Capability}

As per customer's specification, the PCB with height between $0.5 \pm 0.05$ millimeters was not considered as a reject. Next, it was important to find out whether the height of PCBs coming out of current printing process was within the customer's specification or not. In order to find out whether the printing process was capable or not, the samples from the process were collected and the height of the PCB was measured. The result of the current study is shown in Figure 17.

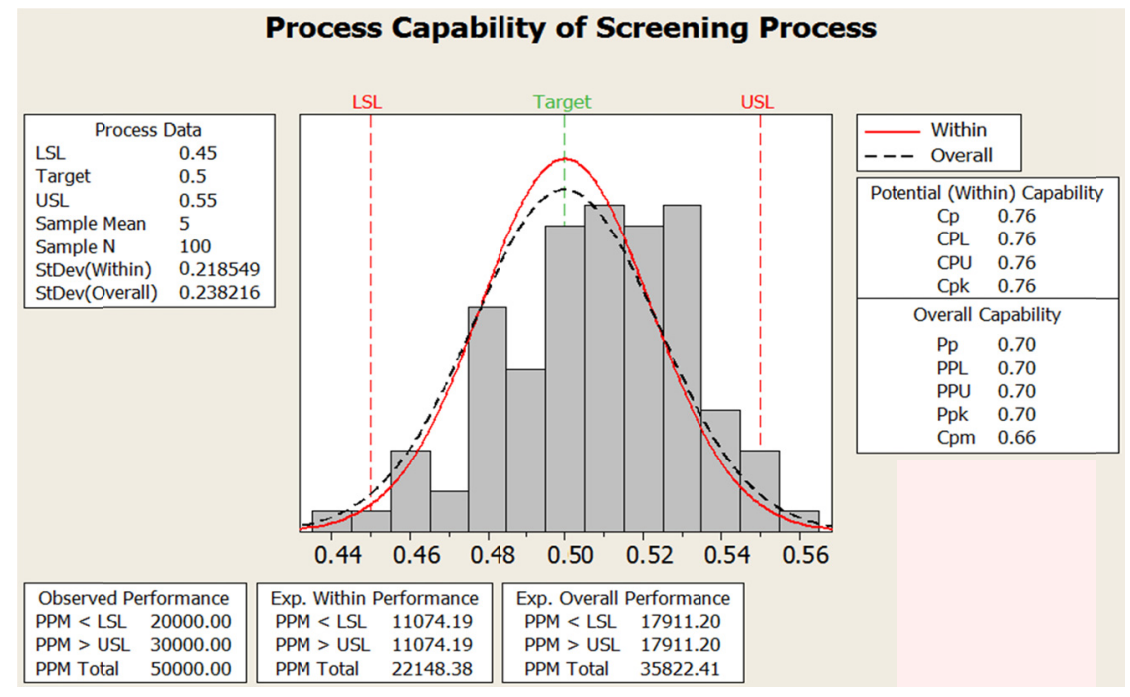

Figure 17. Process capability of printing process

The result showed that the current process was operating at both above the upper specification limit and below the lower specification limit. Although, $\mathrm{Cp}=\mathrm{Cpk}=0.76$, it means the process is centered. But the total $\mathrm{PPM}=35822(\approx 3.5$ sigma level) revealed that the current printing process was not capable of producing the PCB well within the customer specification.

\subsection{Analyze Phase}

According to the results of measure phase, the current process capability in this case was not satisfactory. Although, another capability index displayed $\mathrm{Cpk}=\mathrm{Cp}$, this showed that the printing process was not out off-centre. But, there was a high variance in the solder paste height that needs to be solved.

For investigation the manufacturing process problem required the understanding of different process parameters that influenced quality of the PCB. To better understand the printing process, various process parameters and their effect on 
the quality of the PCBs, the study case also carried out the cause-and-effect diagram for PCB. The current case went through a brainstorming session to identify the most concerned sources of the PCB defect. The outcome was summarized in a cause-and-effect diagram in Figure 18. The root causes for PCB defects were classified into five major categories, which are human, environment, solder paste, printing process and tooling.

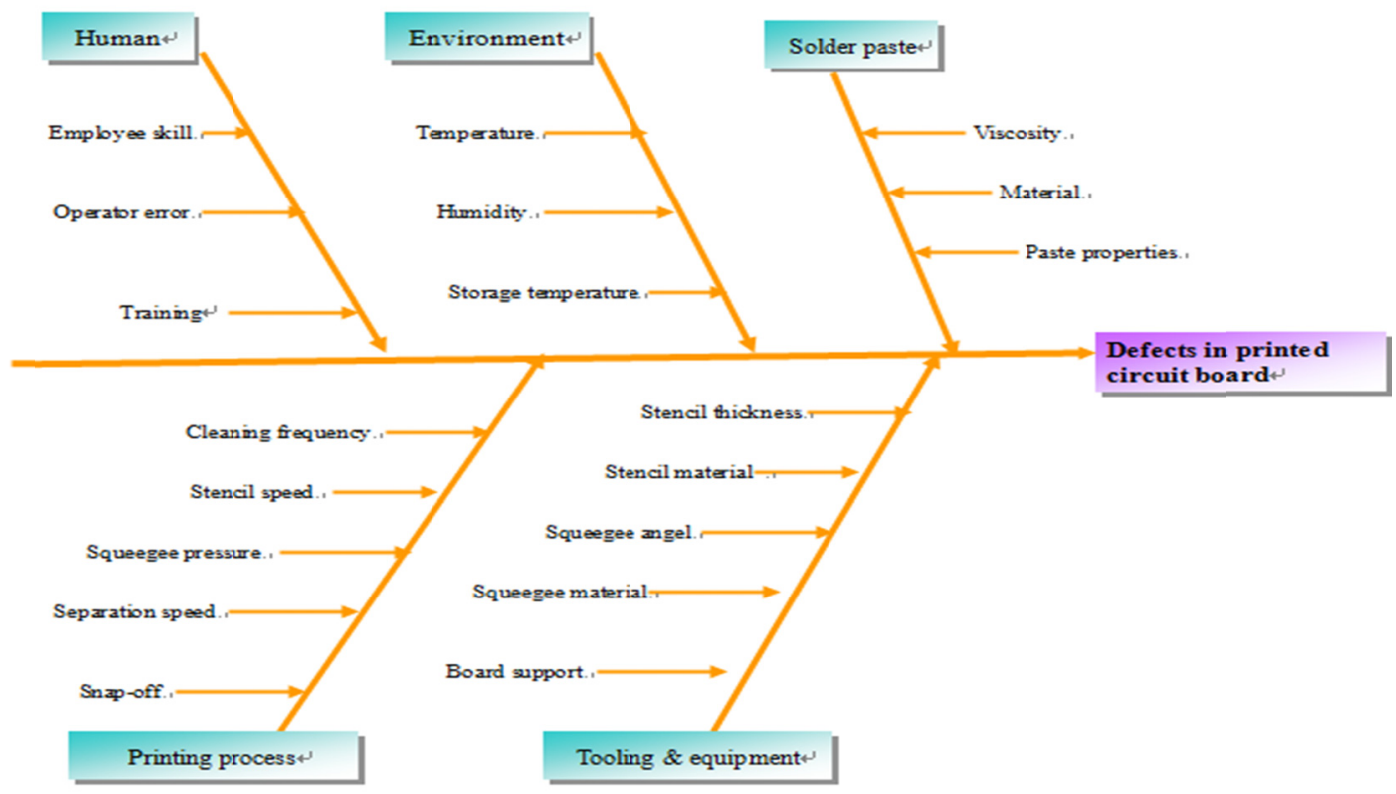

Figure 18. Cause-and-effect diagram for PCB

For the human category, the problem could be due to operator's lack of experience and training. Defect might occur when employee carried out the process without following the work instructions or methods. The number of defects could increase due to improper handling when operators got access to printer setting.

From the solder paste, several paste characteristics must be carefully controlled to achieve optimum production results. These include: percent of metal, viscosity, slump, solder balls, flux activity working life and shelf life. As there was operator-to-operator variation in determining the solder paste volume. The refill volume of the solder paste for each printing might be different for different operators. Therefore, the solder paste volume might be the reason for PCB defects.

Environment: Dust and dirt from the air that ends up on the PCBs and stencils can cause defects such as bridging and poor wet-ability in the reflow soldering process. A small piece of fiber or hair between two fine pitch solder pads can easily cause bridging. It is therefore very important that the PCBs are stored in sealed packages and if necessary, cleaned before use. Air draught in the production area can speed up evaporation of the solvents in the solder paste and thereby makes the solder paste dry out. High temperature can also make the solder paste dry out quickly. If the room temperature in the production area varies a lot, it will be very difficult to control the printing process. The viscosity of the solder paste changes with the temperature and the solder paste print will sometimes be perfected and at other times, paste will slump and result in bridging. The temperature window is between $21-25^{\circ} \mathrm{C}$.

Printing process: Printing Parameters are the most important factors in the solder paste printing process to achieve better yield.

The squeegee pressure: It should be as low as possible to scrape the stencil clean of solder paste particles when printing. The amount of pressure is determined by the printing speed and stencil type. The printing speed is usually recommended by paste manufacturer typically between 20 and $80 \mathrm{~mm}$ per second.

Snap-off: is the distance between the stencil underside and the PCB placed in print position but without the squeegee touching the stencil. For metal stencil printing, the snap off is zero and also called contact printing. A high snap off will result in a thicker layer of solder paste.

The speed of separation between stencil and PCB after printing is important. A too rapid separation speed when printing fine pitch will result in clogging of the stencil apertures. It will also result in tailing and formation high of edges around the solder paste deposits. 
Cleaning: can be done either manually or automatically. The wiper does not clean the stencils underside but simply move the solder paste particles from around the apertures to the complete stencils underside. Stencil cleaning prior to use is important to prevent dust and dirt from entering the solder joints. If all printing parameters are in control, stencil underside cleaning is not necessary.

Tooling \& equipment: the defects of PCB are greatly influenced by stencil thickness, stencil material, design of squeegee and raw boards.

\subsection{Improve Phase}

In the analysis of the current printing performance, the result showed that the printing process capability was not satisfactory. Redesign and printing process reconstruction were not considered to be cost effective in the initial phase. Hence, it was decided to work on process parameters to deal with the PCBs defect. Taguchi method was chosen as an improvement tool to reduce PCB problem by finding optimum settings of all the Critical to Quality (CTQ) input factors in the printing process. The Taguchi steps are defined as identifying the response or output, identifying factors for the study, determination of factor levels and range of factor setting, choice of appropriate experimental design, run the experiment, collect and analyze the data, draw conclusion and act on the results. Steps taken to complete the Taguchi are discussed below.

\subsubsection{Define the Goal of the Experiment}

The goal of the experiment was to determine the most significant factors affecting the quality of product and their interactions. Then, subsequently reducing or eliminating the PCB defect.

\subsubsection{Specify the Input Parameters and Output Response to Be Measured}

Based on literature reviews and process engineering, the study was decided to select some factors that might influence the printing process. The eight factors chosen and their actual low and high levels are as follow:

Table 7. Factors and corresponding level of input parameters

\begin{tabular}{lll}
\hline \multicolumn{1}{c}{ Factors } & \multicolumn{1}{c}{ Low Level } & High Level \\
\hline A - Printing speed & $30 \mathrm{~mm} / \mathrm{sec}$ & $60 \mathrm{~mm} / \mathrm{sec}$ \\
B - Side of stencil & Left & Right \\
C - Pressure of squeegee & $4 \mathrm{~kg}$ & $7 \mathrm{~kg}$ \\
D - Snap-off & $-0.1 \mathrm{~mm}$ & $0.1 \mathrm{~mm}$ \\
E - Solder paste volume & Small & Large \\
F - Blade type & Front & Back \\
G - Cleaning interval & $5 \mathrm{~s}$ & $10 \mathrm{~s}$ \\
H - Separation speed & $1 \mathrm{~mm} / \mathrm{s}$ & $5 \mathrm{~mm} / \mathrm{s}$ \\
\hline
\end{tabular}

$\begin{array}{lll}\text { Input Variables } & \text { Process } & \text { Response }\end{array}$

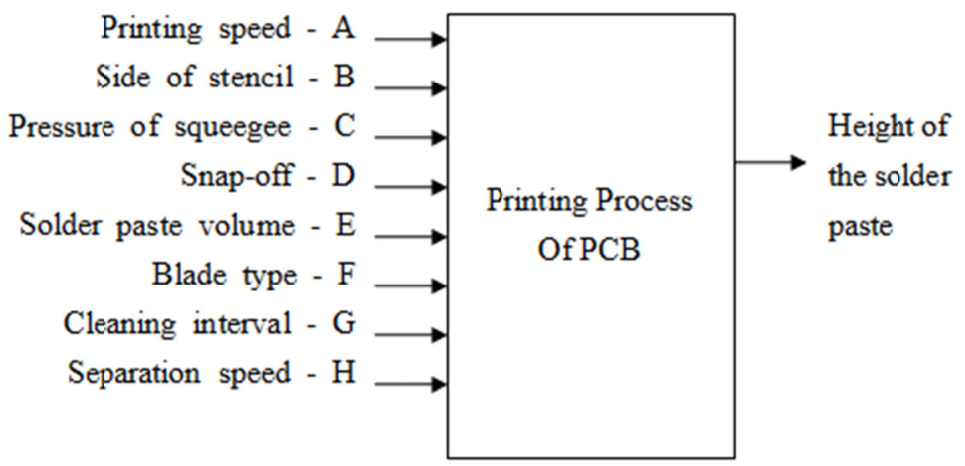

Figure 19. Input and response of printing process 
The height of solder paste was determined to be the output response. The range of PCB with height between 0.45 and $0.55 \mathrm{~mm}$ does not considered as rejected PCB.

\subsubsection{Using Taguchi Method Finds Some Critical Factors}

One of the complete factorial experiments is $n k$ factorial designs; $\mathrm{k}$ is the number of factors investigated at $\mathrm{n}$ levels. In order to calculate the number of runs, e.g. if $n=2, k=5$ then the number of runs is $25=32$ runs. The number of run increases as the $\mathrm{k}$ value increases. To solve this complexity, the Taguchi method uses a special design of orthogonal array to study the entire process parameter space with a small number of experiments only. In this step, the study case will use Taguchi method to reduce some factors that are not properly significant. Using Minitab created the Orthogonal Array L16:

Table 8. Using Minitab to create the Orthogonal Array L16

\begin{tabular}{lllllllll}
\hline $\begin{array}{c}\text { A } \\
\text { Printing } \\
\text { speed } \\
(\mathrm{mm} / \mathrm{s})\end{array}$ & $\begin{array}{c}\text { Side of } \\
\text { stencil }\end{array}$ & $\begin{array}{c}\text { C Pressure } \\
\text { of squeegee } \\
(\mathrm{kg})\end{array}$ & $\begin{array}{c}\text { D Snap } \\
\text { off } \\
(\mathrm{mm})\end{array}$ & $\begin{array}{c}\text { E Solder } \\
\text { paste } \\
\text { volume }\end{array}$ & $\begin{array}{c}\text { F Blade } \\
\text { type }\end{array}$ & $\begin{array}{c}\text { G } \\
\text { Cleaning } \\
\text { interval } \\
(\mathrm{s})\end{array}$ & $\begin{array}{c}\text { H Separation } \\
\text { speed } \\
(\mathrm{mm} / \mathrm{s})\end{array}$ & Height \\
\hline 30 & left & 4 & -0.1 & Small & Front & 5 & 1 & 0.434 \\
30 & left & 4 & 0.1 & Small & Back & 10 & 5 & 0.463 \\
30 & left & 7 & -0.1 & Large & front & 10 & 5 & 0.513 \\
30 & left & 7 & 0.1 & Large & back & 5 & 1 & 0.552 \\
30 & right & 4 & -0.1 & Large & back & 10 & 1 & 0.484 \\
30 & right & 4 & 0.1 & Large & front & 5 & 5 & 0.425 \\
30 & right & 7 & -0.1 & Small & back & 5 & 5 & 0.506 \\
30 & right & 7 & 0.1 & Small & front & 10 & 1 & 0.558 \\
60 & left & 4 & -0.1 & Large & back & 5 & 5 & 0.463 \\
60 & left & 4 & 0.1 & Large & front & 10 & 1 & 0.568 \\
60 & left & 7 & -0.1 & Small & back & 10 & 1 & 0.565 \\
60 & left & 7 & 0.1 & Small & front & 5 & 5 & 0.539 \\
60 & right & 4 & -0.1 & Small & front & 10 & 5 & 0.476 \\
60 & right & 4 & 0.1 & Small & back & 5 & 1 & 0.481 \\
60 & right & 7 & -0.1 & Large & front & 5 & 1 & 0.526 \\
\hline
\end{tabular}




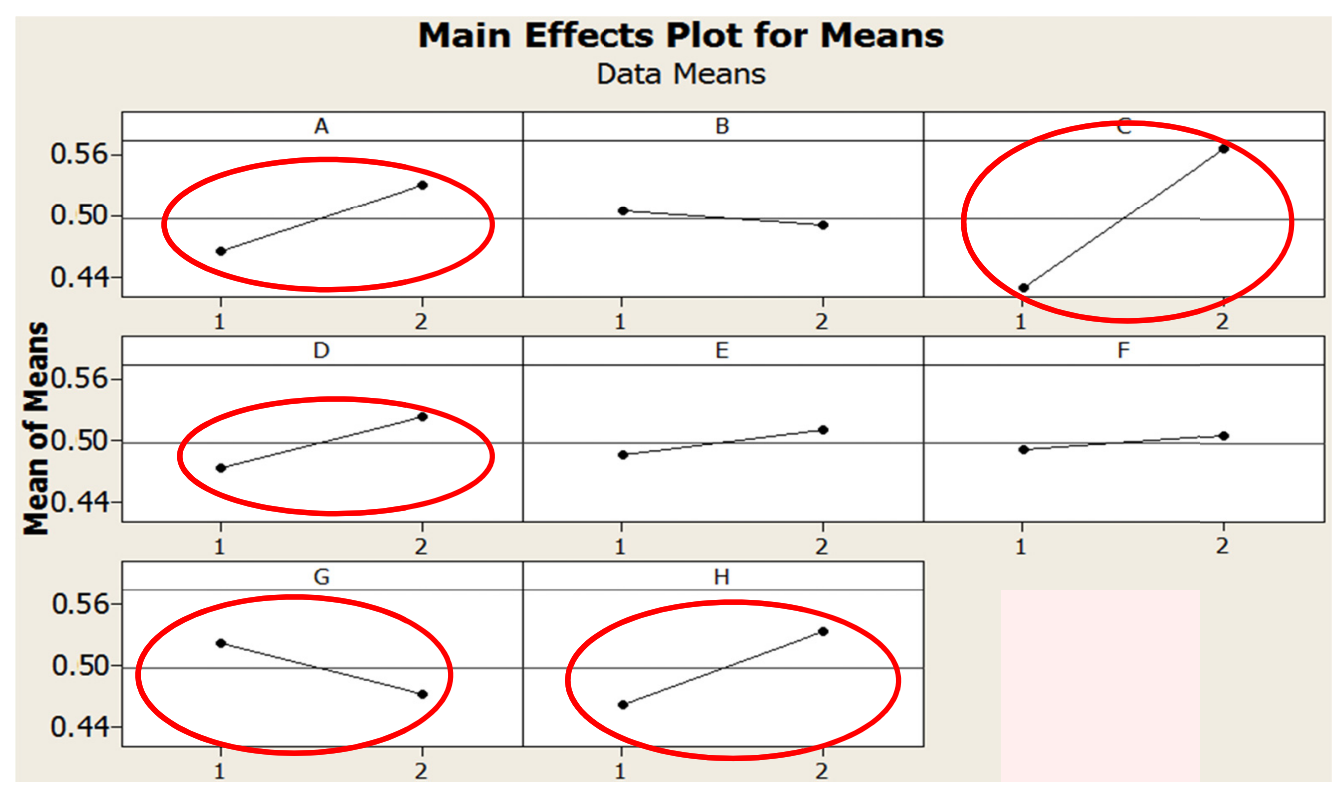

Figure 20. Main effect plots for height average

After carrying out the Orthogonal Array L16 from the data in Table 8, the main effect plots for height average of eight factors are obtained. From the main effect plots shown in Figure 20, there are five factors that were significant factors for the height average: printing speed-A, pressure of squeegee-C, snap-off-D, cleaning interval- $\mathrm{G}$ and separation speed-H. And the side of stencil-B, solder paste volume-E and blade type-F, were not significant factors.

\subsubsection{Further Experiment for Five Significant Factors}

In further experiment, this study research five determined significant factors with more careful level. The five significant factors were found and their actual three levels are as follows:

Table 9. Levels of five significant factors

\begin{tabular}{lccc}
\hline Factors & Level 1 & Level 2 & Level 3 \\
\hline (A) Printing speed (mm/s) & 30 & 50 & 70 \\
(C) Pressure of squeegee (kg) & 4 & 6 & 8 \\
(D) Snap off (mm) & -0.1 & 0 & 0.1 \\
(G) Cleaning interval (s) & 4 & 7 & 10 \\
(H) Separation speed (mm/s) & 1 & 3 & 5 \\
\hline
\end{tabular}

In this study, two potential nuisance factors; temperature and humidity that was felt that large variation in these factors could potentially adversely affect the experimental results. Therefore, the study decided to hold these factors constant during the experiment. The experimental conditions are as follows:

Room temperature: $25 \mathrm{oC}$

Room humidity: $58 \%$

Number of operators: 1

Specification: 0.45-0.55 millimeter.

The orthogonal array (OA) L27 was used for this study. Since five factors, three levels of each factor were studied in this research. Figure 21 shows the layout of L27 OA and the recorded output response values of height. 


\begin{tabular}{|c|c|c|c|c|c|c|c|}
\hline & (A) Printing speed $(\mathrm{mm} / \mathrm{s})$ & (C) Pressure of squeegee (kg) & (D) Snap off (mm) & (G) Cleaning interval (s) & (H) Separation speed $(\mathrm{mm} / \mathrm{s})$ & Height1 & Height2 \\
\hline 1 & 30 & 4 & -0.1 & 4 & 1 & 0.446 & 0.452 \\
\hline 2 & 30 & 4 & -0.1 & 4 & 3 & 0.453 & 0.456 \\
\hline 3 & 30 & 4 & -0.1 & 4 & 5 & 0.439 & 0.430 \\
\hline 4 & 30 & 6 & 0.0 & 7 & 1 & 0.474 & 0.481 \\
\hline 5 & 30 & 6 & 0.0 & 7 & 3 & 0.483 & 0.461 \\
\hline 6 & 30 & 6 & 0.0 & 7 & 5 & 0.472 & 0.462 \\
\hline 7 & 30 & 8 & 0.1 & 10 & 1 & 0.505 & 0.515 \\
\hline 8 & 30 & 8 & 0.1 & 10 & 3 & 0.514 & 0.524 \\
\hline 9 & 30 & 8 & 0.1 & 10 & 5 & 0.494 & 0.478 \\
\hline 10 & 50 & 4 & 0.0 & 10 & 1 & 0.526 & 0.512 \\
\hline 11 & 50 & 4 & 0.0 & 10 & 3 & 0.454 & 0.463 \\
\hline 12 & 50 & 4 & 0.0 & 10 & 5 & 0.542 & 0.555 \\
\hline 13 & 50 & 6 & 0.1 & 4 & 1 & 0.503 & 0.494 \\
\hline 14 & 50 & 6 & 0.1 & 4 & 3 & 0.458 & 0.458 \\
\hline 15 & 50 & 6 & 0.1 & 4 & 5 & 0.469 & 0.458 \\
\hline 16 & 50 & 8 & -0.1 & 7 & 1 & 0.520 & 0.531 \\
\hline 17 & 50 & 8 & -0.1 & 7 & 3 & 0.523 & 0.503 \\
\hline 18 & 50 & 8 & -0.1 & 7 & 5 & 0.487 & 0.469 \\
\hline 19 & 70 & 4 & 0.1 & 7 & 1 & 0.563 & 0.549 \\
\hline 20 & 70 & 4 & 0.1 & 7 & 3 & 0.542 & 0.548 \\
\hline 21 & 70 & 4 & 0.1 & 7 & 5 & 0.493 & 0.504 \\
\hline 22 & 70 & 6 & -0.1 & 10 & 1 & 0.553 & 0.540 \\
\hline 23 & 70 & 6 & -0.1 & 10 & 3 & 0.477 & 0.484 \\
\hline 24 & 70 & 6 & -0.1 & 10 & 5 & 0.513 & 0.527 \\
\hline 25 & 70 & 8 & 0.0 & 4 & 1 & 0.533 & 0.505 \\
\hline 26 & 70 & 8 & 0.0 & 4 & 3 & 0.525 & 0.514 \\
\hline 27 & 70 & 8 & 0.0 & 4 & 5 & 0.538 & 0.527 \\
\hline
\end{tabular}

Figure 21. Taguchi L27 orthogonal array design

\subsubsection{Collect and Analyze the Experimental Data}

Taguchi defined three categories of quality characteristics in the analysis of Signal to noise $(\mathrm{S} / \mathrm{N})$ ratio, i.e. the smaller-the-better, larger-the-better and the nominal-the-better. The $\mathrm{S} / \mathrm{N}$ ratio for each level of process parameter is computed based on the $\mathrm{S} / \mathrm{N}$ analysis.

*) Signal to Noise ratio analysis:

The height of PCBs that obtained in experiment was used to calculate the signal-to-noise ( $\mathrm{S} / \mathrm{N})$ ratio. In determination of $\mathrm{S} / \mathrm{N}$ ratio, the nominal-the-better quality characteristic has been selected for this study. Regardless of the category of the quality characteristic, a larger $\mathrm{S} / \mathrm{N}$ noise ratio corresponds to better quality characteristics. Therefore, the optimal level of process parameter is the level of highest $\mathrm{S} / \mathrm{N}$ ratio.

For nominal the better,

$$
\frac{S}{N}=-10 \log \left(\frac{1}{n} \sum_{i=1}^{n}\left(\mathrm{y}_{\mathrm{i}}-m\right)^{2}\right.
$$

Where, $\mathrm{n}$ : Number of experiment, yi $=$ Experimental values, $\mathrm{m}$ : Target value

Taguchi design module in MINITAB software version 15 was used to analysis data. The results obtained were shown in Figures 22, 23, 24 and Table 10. 
Table 10. Signal to noise for each experiment

\begin{tabular}{cccc}
\hline Experiment No. & S/N Value & Experiment No. & S/N Value \\
\hline 1 & 40.4922 & 15 & 35.5034 \\
2 & 46.6186 & 16 & 36.5939 \\
3 & 36.6852 & 17 & 31.1920 \\
4 & 39.6878 & 18 & 31.4934 \\
5 & 29.6407 & 19 & 34.9892 \\
6 & 36.3966 & 20 & 42.1752 \\
7 & 37.1617 & 21 & 36.1357 \\
8 & 37.3136 & 22 & 35.4832 \\
9 & 32.6606 & 23 & 39.7422 \\
10 & 34.3911 & 24 & 34.4078 \\
11 & 37.1522 & 25 & 28.3705 \\
12 & 35.5150 & 26 & 36.4942 \\
13 & 37.8788 & 27 & 36.7088 \\
\hline
\end{tabular}

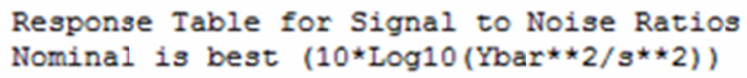

(A)

Printing speed $(\mathrm{mm} / \mathrm{s})$ 37.41

34.63

36.06

2.77

2
(C) Pressure of squeegee $\frac{(\mathrm{kg})}{38.24}$ 35.64 34.22 4.02 1

\begin{tabular}{r} 
(D) Snap \\
of $(\mathrm{mm})$ \\
\hline 36.97 \\
\hline 34.93 \\
36.20 \\
2.04 \\
3
\end{tabular}

(H) Separation speed $(\mathrm{mm} / \mathrm{s})$ 36.12

36.92

35.06

1.87

Figure 22. Response for signal to noise ratios

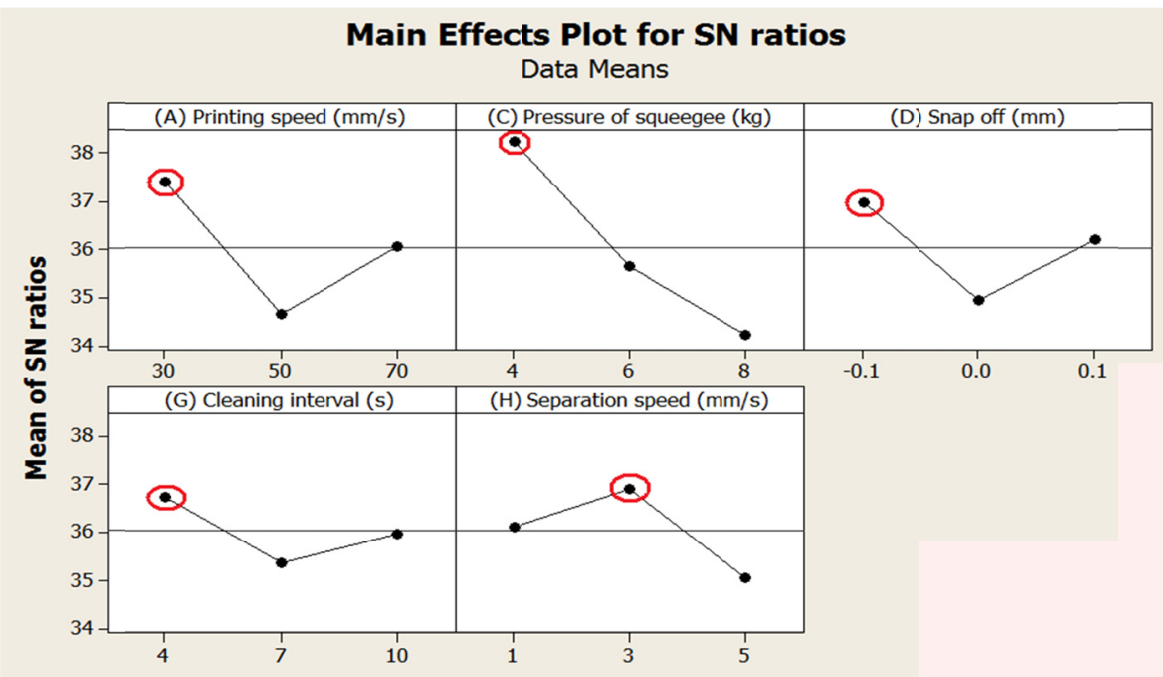

Signal-to-noise: Nominal is best (10*Log10(Ybar**2/s**2))

Figure 23. Main effects plot for $\mathrm{SN}$ ratios 
Response Table for Means

(A)

Printing
speed
$(\mathrm{mm} / \mathrm{s})$
0.4744
0.4949
0.5242
0.0498
1

(C) Pressure

of squeegee

$(\mathrm{kg})$

0.4959

0.4862

0.5114

0.0252

3
(D) Snap

off (mm)

0.4891

0.5015

0.5029

0.0139

$\begin{array}{rr} & \begin{array}{r}(\mathrm{H}) \\ \text { Separation } \\ \text { speed }\end{array} \\ \text { interval Cleaning } & \begin{array}{r}\mathrm{s}) \\ (\mathrm{mm} / \mathrm{s})\end{array} \\ 0.4801 & 0.5112 \\ 0.5036 & 0.4902 \\ 0.5098 & 0.4921 \\ 0.0297 & 0.0210 \\ 2 & 4\end{array}$

Figure 24. Response table for means

From the $\mathrm{S} / \mathrm{N}$ ratio response in Figure 22, the best set of combination parameter can be determined by selecting the level with the highest $\mathrm{S} / \mathrm{N}$ ratio value of each factor. Thus, the result that obtained is factor A aligned with level 1 (A1), follow up C1, D1, G1 and $\mathrm{H} 2(30 ; 4 ;-0.1 ; 4 ; 3)$. This result can also be observed from Main effects plot for SN ratios diagram in Figure 23. Besides that, the delta between factors in Figure 24 also shows which factor is more significant. The most significant factor that affects to height of the solder paste is printing speed followed up cleaning interval; pressure of squeegee; separation speed and snap off.

\subsubsection{Define the Optimum Conditions and Solutions}

From the data that has been analyzed, the optimal setting for solder paste printing process was obtained. The optimal setting was as follows:

A- Printing speed $(30 \mathrm{~mm} / \mathrm{s})$.

$\mathrm{C}$ - Squeegee pressure $(4 \mathrm{~kg})$.

D- Snap-off (-0.1 mm).

$\mathrm{G}-$ Separation speed $(4 \mathrm{~mm} / \mathrm{s})$.

$\mathrm{H}-$ Cleaning interval (3 s).

By using these optimal settings, the variation of the solder paste height can be reduced. After reducing the height variation, the sigma level of the printing process can be improved.

\subsubsection{Verification of the Determined Settings}

Before applying the determined settings to the whole manufacturing operation and producing a high volume of PCBs, these settings are necessary to run some verification runs that were demanded to inspect the reproducibility and predictability of the results. For this experiment, thirty sequential PCBs were applied with the determined settings in the printing process. After that the height of the PCBs were measured. The height measured of the thirty samples was shown in Table 11, and the experimental settings were shown in Table 12.

Table 11. Height of thirty PCBs measured from verification runs

\begin{tabular}{llll}
\hline Sample & Height $(\mathbf{m m})$ & Sample & Height $(\mathbf{m m})$ \\
\hline 1 & 0.485 & 16 & 0.507 \\
2 & 0.502 & 17 & 0.497 \\
3 & 0.478 & 18 & 0.459 \\
4 & 0.512 & 19 & 0.480 \\
5 & 0.509 & 20 & 0.510 \\
6 & 0.524 & 21 & 0.508 \\
7 & 0.461 & 22 & 0.511 \\
8 & 0.503 & 23 & 0.540 \\
9 & 0.491 & 24 & 0.472 \\
\hline
\end{tabular}




\begin{tabular}{llll}
\hline 10 & 0.482 & 25 & 0.511 \\
11 & 0.534 & 26 & 0.508 \\
12 & 0.471 & 27 & 0.484 \\
13 & 0.483 & 28 & 0.469 \\
14 & 0.501 & 29 & 0.502 \\
15 & 0.512 & 30 & 0.522 \\
\hline
\end{tabular}

Table 12. Process parameter setting for the verification runs

\begin{tabular}{cccccc}
\hline Factors & $\begin{array}{c}\mathrm{A} \\
\text { Printing speed } \\
(\mathrm{mm} / \mathrm{s})\end{array}$ & $\begin{array}{c}\mathrm{C} \\
\text { Squeegee pressure } \\
(\mathrm{kg})\end{array}$ & $\begin{array}{c}\mathrm{D} \\
\text { Snap-off }(\mathrm{mm})\end{array}$ & $\begin{array}{c}\mathrm{G} \\
\text { Separation speed } \\
(\mathrm{mm} / \mathrm{s})\end{array}$ & $\begin{array}{c}\mathrm{H} \\
\text { Cleaning } \\
\text { interval }(\mathrm{s})\end{array}$ \\
\hline Setting & 30 & 4 & -0.1 & 4 & 3 \\
\hline
\end{tabular}

Control chart plotted from the height data in Table 11 to verify the determined settings. Figure 25 shown the height of the PCBs was in control.

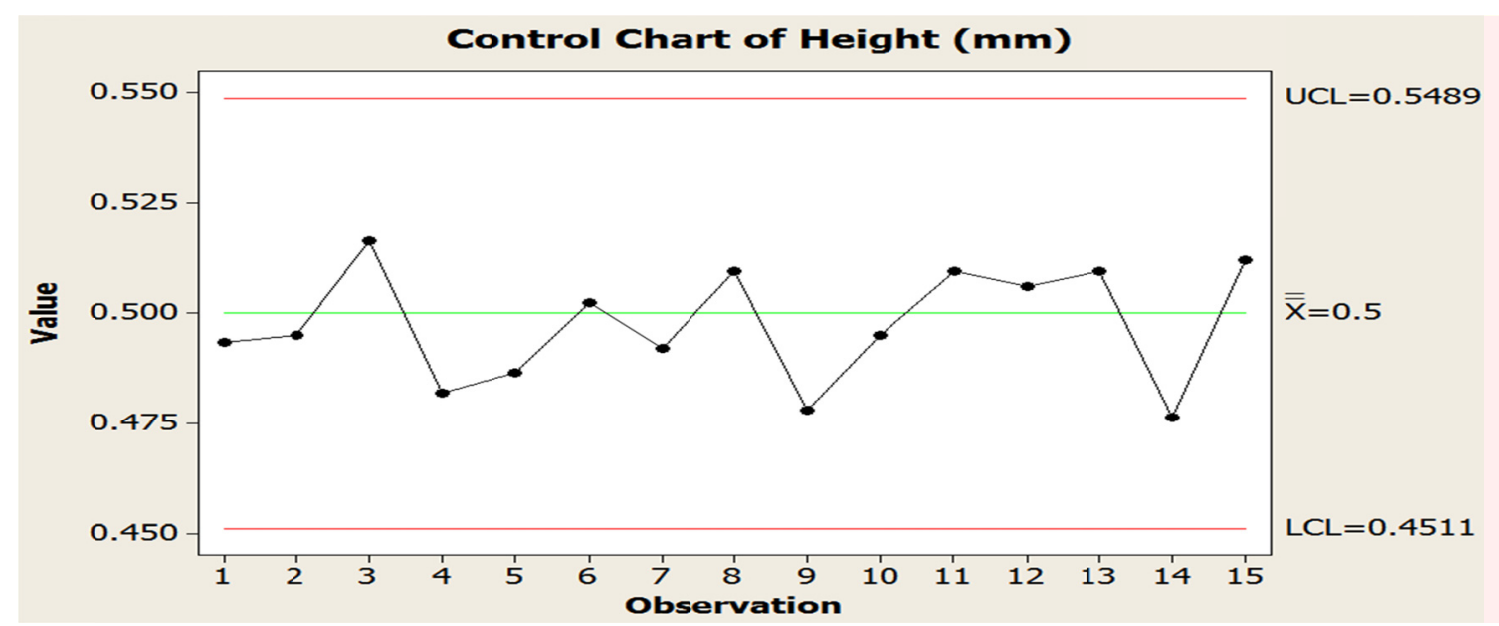

Figure 25. Control chart for height in verification runs

\subsection{Control Phase}

To obtain the improvement of the sigma level in the screening process, some control strategies were recommended for the study. For example, the CTQ input factors should be monitored by control charts over time, so that the solder paste height variation and the sigma level can be controlled continuously. The description of the recommended control strategies are provided as below:

Printing speed: The relatively low printing speed $(30 \mathrm{~mm} / \mathrm{s})$ is recommended as far as this low speed can optimize the printing performance of the printing process. The fast printing speed can make the solder paste height that will be lower than necessary height.

Squeegee pressure: A low squeegee pressure $(4 \mathrm{~kg})$ should be set for the prevention the solder paste was excessive in lines or joints on the circuit board. And the low squeegee pressure can be increased progressively as the duration of using the stencil (age of stencil).

And according to the experimental results: Snap-off (-0.1 mm); Separation speed (4 mm/s); Cleaning interval (3s) can reduce height variation within the board and hence can approach better printing performance in the screening process. 


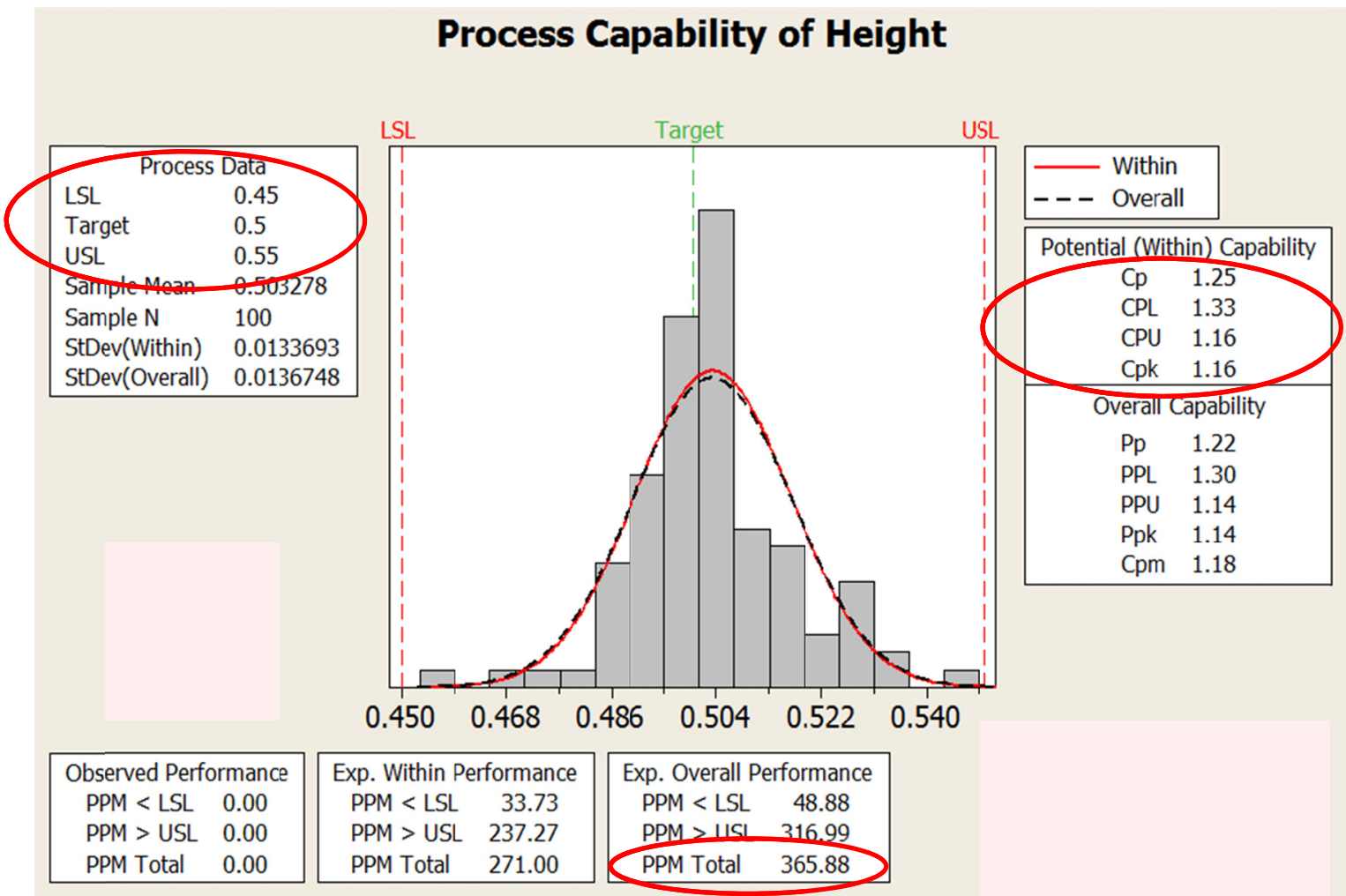

Figure 26. Process capability of printing process after using optimal setting

Table 13. Comparison of printing performance before and after using optimal settings

\begin{tabular}{lccccc}
\hline Comparison & Mean & Cp & Cpk & Sigma level & ppm \\
\hline Before & 0.5 & 0.76 & 0.76 & 3.5 & 35822 \\
After & 0.503 & 1.25 & 1.16 & 5.0 & 365.88 \\
\hline
\end{tabular}

By using these optimal settings, the variation of the solder paste height can be reduced, and therefore the sigma level of the printing process in the study case can be improved. The comparison of the printing performance before and after using the optimal settings is shown in Table 13. After using the optimal settings, the sigma level of the screening process can be improved from 3.5 to 5 . This shows that a nearly six-sigma level performance can be approached. As a result, the cost of quality for the company is significantly reduced.

There have already been obvious improvements from the improvement stage, and the set targets have been achieved. Therefore, it is necessary to maintain the improvements in the controlling stage, so that the improvement results can be sustained. The operations in this stage are as follows:

\subsubsection{Implementing the Process Control Plan}

A controlling and monitoring system is established by focusing on the five factors key of processes: printing speed, pressure of squeegee, snap off, separation speed and cleaning interval and appropriately monitoring their operations.

Master cycle sheet will be maintained so that parameter settings will be in place.

Control chart will be plotted of the height data to monitor the printing process.

\subsubsection{Establishing Standard Documentation}

Standard operating procedures (SOP) are created in the same manner as the establishment of the control plan. Standard documentations and forms will be established to act as a reference for the future process improvement. 


\section{Conclusions and Future Works}

\subsection{Limitations and Conclusions}

The objectives of this research are to resolve quality related problems in printing process of manufacturing PCBs and using Six Sigma DMAIC to improve quality of the products. The goals of this study are: to research and understand printing process in printed circuit board manufacturing (PCB), to evaluate and research quality problems in a PCBs company, to research and apply statistical software that is MiniTab version 15, and to solve the quality problem of printing process, increase quality of PCBs with the optimal factors and levels are: A1 $(30 \mathrm{~mm} / \mathrm{s}) ; \mathrm{C} 1(4 \mathrm{~kg}) ; \mathrm{D} 1$ $(-0.1 \mathrm{~mm}) ; \mathrm{G} 1(4 \mathrm{~mm} / \mathrm{s}) ; \mathrm{H} 2(3 \mathrm{~s})$.

The results show that Six Sigma DMAIC methodology can be used to improve the quality of a PCB product, the printed circuit board company was applied. The printing process and defects in circuit boards were studied. In the improve phase of the DMAIC approach, Taguchi method was used to design experiment and analyze the Signal to Noise ratio. By using the optimal settings, the sigma level of the printing process can be improved, and hence a nearly Six Sigma level performance can be achieved. Unquestionable, Taguchi is the core statistical tools for Six Sigma improvement. It is recommended that successful implementation of the DMAIC approach in the printing process should be translated to similar manufacturing processes in the PCB industry.

\subsection{Future Works}

Obviously, by using these optimal settings, the variation of the solder paste height can be reduced, and therefore the sigma level of the printing process in the study case can be improved from 3.5 to 5 . The $5 \mathrm{Six}$ Sigma level is acceptable for this study case because the defect level in parts per million (PPM) is reduced from 35822 to 365 defects. It means the current printing process is also improved about 90\%. In this study, the Orthogonal Array L27 is used to study the influence of five significant factors on the solder paste height and to draw conclusions. In the future, a full factorial experiment will be carried out. Because by using the full factorial experiment, we can also evaluate even the interactions between the factors. When knowing the interactions, the sigma level of the printing process will be able to be more improved. It is also suggested that the company extend the designed experiments to different machine, so that the optimal settings can be applied to all machines.

\section{References}

Antony, J., \& Banuelas, R. (2002). Key Ingredients for The Effective Implementation Of Six Sigma Program. Measuring Business Excellence, 6, 20-27. http://dx.doi.org/10.1108/13683040210451679

Coronado, B., \& Antony, J. (2002). Critical Success Factors For The Successful Implementation Of Six Sigma Projects in Organizations. The TQM Magazine, 14, 92-99. http://dx.doi.org/10.1108/09544780210416702

Harry, M., \& Schroeder, R. (2000). Six Sigma: The Breakthrough Strategy Revolutionizing The World's Top Corporation. Doubleday Business, New York.

Hoerl, R. W. (2001). Six sigma Black Belts: What do they need to Know. Journal of Quality Technology, 33, 391-406.

Lee-Mortimer, A. (2006). A Vital Improvement Approach. Assembly Automation, 26, 10-17. http://dx.doi.org/10.1108/01445150610645602

Lynch, D. P., Bertoline, S., \& Cloutier, E. (2003). How to Cope With DMAIC Projects. Quality Progress, 36, 37-41.

Mcadam, R., \& Evans, A. (2004). Challenge to six Sigma in a High Technology Mass-Manufacturing Environments. The Total Quality Management Magazine, 699-706. http://dx.doi.org/10.1080/14783360410001680189

Montgomery, D. C. (2008). Introduction to Statistical Quality Control (6 ${ }^{\text {th }}$ ed.). Wiley, New York.

Nguyen, N. T., \& Tran, T. T. (2015). Mathematical Development and Evaluation of Forecasting Models for Accuracy of Inflation in Developing Countries: A Case of Vietnam. Discrete Dynamics in Nature and Society, 2015. http://dx.doi.org/10.1155/2015/858157.

Nguyen, N. T., Tran, T. T., Wang, C. N., \& Nguyen, N. T. (2015). Optimization of Strategic Alliances by Integrating DEA and Grey Model. Journal of Grey System, 27(1).

Savolainen, T., \& Haikonen, A. (2007). Dynamics of Organizational Learning and Continuous Improvement in six Sigma Implementation. The TQM Magazine, 19, 6-17. http://dx.doi.org/10.1108/09544780710720808

Szeto, A.Y.T., \& Tsang, A.H.C. (2005). Antecedent to Successful Implementation of Six Sigma. International Journal of Six Sigma and Competitive Advantage, 1, 307-322. http://dx.doi.org/10.1504/IJSSCA.2005.008094 